\title{
Dietary Practices During Common Religious Fasts in People with Type 2 Diabetes Mellitus Among Different Religions in North India-A Questionnaire-based Study
}

\author{
Lovely Gupta, ${ }^{1}$ Bhavneet Arora, ${ }^{2}$ Deepak Khandelwal, ${ }^{3}$ Priti Rishi Lal, ${ }^{1}$ Sanjay Kalra, ${ }^{4}$ Saptarshi Bhattacharya, ${ }^{5}$ \\ Deep Dutta, ${ }^{6}$ Sachin Chittawar ${ }^{7}$ and Ankit Paliwal ${ }^{2}$ \\ 1. Department of Food and Nutrition, Lady Irwin College, University of Delhi, New Delhi, India; 2. Department of Food and Nutrition, Amity Institute \\ of Food Technology, Amity University Noida, Uttar Pradesh, India; 3. Department of Endocrinology, Maharaja Agrasen Hospital, Punjabi Bagh, \\ New Delhi, India; 4. Department of Endocrinology, Bharti Hospital, Karnal, Haryana, India; 5. Department of Endocrinology, Max Super-specialty \\ Hospital, Patparganj, New Delhi, India; 6. Department of Endocrinology, Center for Endocrinology Diabetes Arthritis \& Rheumatism (CEDAR) \\ Superspecialty Clinics, Dwarka, New Delhi, India; 7. Division of Endocrinology, Department of Medicine, Gandhi Medical College (GMC) and \\ Hamidia Hospital, Bhopal, India
}

DOl: https://doi.org/10.17925/USE.2020.16.1.36

$\mathrm{B}$ ackground: There are no data regarding dietary practices during fasts in subjects with type 2 diabetes mellitus (T2DM) among different religions in India, specifically Hindus. The aim of this study was to assess dietary patterns and practices during fasts among subjects with T2DM in India. Methods: Participants with T2DM from three diabetes clinics in northern India, after verbal consent, were subjected to predesigned study proforma. Results: Three hundred participants completed the questionnaire (age $\geq 25$ years); $76.33 \%$ were Hindu, $11.00 \%$ were Muslim, 4.66\% were Sikh, and 5.67\% were from other religions (Christians and Buddhists). Overall, $49.33 \%$ participants observed fasts in the last year. The most common Hindu fasts were Navratri (34.50\%) and Karvachauth (31.00\%). Only 1.35\% of participants discussed dietary behavior with their doctors or dieticians before observing the fast. Frequency of eating during fasts varied among different religions, as well as according to different fasts. Common food groups consumed among the two most popular Hindu fasts were milk and milk products $(92.41 \%$ during Navratri and 56.34\% during Karvachauth), fruits (49.37\% during Navratri and 16.90\% during Karvachauth), and cereals (10.13\% during Navratri and $8.45 \%$ during Karvachauth). Direct intake of sugar in the form of sweets/desserts, as well as sugar-containing beverages, juices and soft drinks, was common. Conclusions: Fasting is a common practice among people T2DM in all religions of India. Poor adherence to healthy dietary practices is common during fasting among subjects with T2DM. Many patients do not discuss their fasting habits with their diabetes care team. Diabetes care teams should discuss fasts with their patients with T2DM. They should tailor this information based on the patient's religion and provide them with information regarding diet during days of fast.

\section{Keywords}

Fasts, diabetes, religion, diet, counselling, Navratri, Karvachauth

Disclosure: Lovely Gupta, Bhavneet Arora, Deepak Khandelwal, Priti Rishi Lal, Sanjay Kalra, Saptarshi Bhattacharya, Deep Dutta, Sachin Chittawar, and Ankit Paliwal have no financial or non-financial relationships or activities to declare in relation to this article.

Review Process: Double-blind peer review.

Compliance with Ethics: This was a retrospective, questionnaire-based study and did not involve any experiments with human or animal subjects performed by any of the authors.

Authorship: All named authors meet the criteria of the International Committee of Medical Journal Editors for authorship for this manuscript, take responsibility for the integrity of the work as a whole and have given final approval for the version to be published.

Access: This article is freely accessible at touchENDOCRINOLOGY.com

(C) Touch Medical Media 2020

Received: August 31, 2019

Accepted: October 29, 2019

Published: February 28, 2020

Citation: US Endocrinology. 2020;16(1):36-40

Corresponding Author: Deepak Khandelwal, Department of Endocrinology \& Diabetes, Maharaja Agrasen Hospital, Punjabi Bagh, New Delhi-110 026, India.

E:khandelwalaiims@gmail.com

Support: No funding was received in the publication of this article.
India has a vast diversity of cultures and religions following a vast number of festivals and rituals, irrespective of their caste, creed, age, and status with different rituals. ${ }^{1}$ The Hindu religion constitutes the world's third-largest religion, and $80 \%$ of the Hindu population resides in India and Nepal. ${ }^{2}$ According to the All India Religion Census Data 2011, Hindu religion comprises 79.80\%, Muslim 14.23\%, Christian 2.30\%, Sikh 1.72\%, Buddhist $0.70 \%$, Jain $0.37 \%$, and others $0.66 \%$ of the population. ${ }^{3}$ Many types of fasts are observed by different religions as a ritual meant to purify the body and the mind, and develop the sattvic quality of detachment as a mark of respect to personal gods, or as a part of penance. ${ }^{4,5}$ In the healthy subject, fasting does not have any harmful consequences on health. However, it can induce dehydration, dyselectrolytemia, hypotension, hypoglycemia, and significant hyperglycemia for patients with diabetes. ${ }^{6,7}$ Data regarding religious fasts in subjects with diabetes are primarily available in the context of Ramadan fasting. ${ }^{8-10}$ To the best of our knowledge, there are no data regarding dietary practices during fasts in subjects with type 2 diabetes mellitus (T2DM) among the Hindu religion from India or any other country.

Navratri and Karvachauth among Hindus, and Ramadan among Muslims, are the most common religious fasts observed in India. 
Navratri is one of the festivals most widely celebrated by Hindus in India. It is a 9-day festival devoted to the worship of the goddess Durga. The people observe fasts, worship the goddess (northern India), perform "garba" and "dandiya-raas" dances (western India), and follow unique tradition-bound activities in different states with different cultural beliefs. ${ }^{4}$ Similarly, during Karvachauth, Hindu women observe a long day fast for about 12-15 hours, usually without even consuming water, and pray for their husband's long-life good health. ${ }^{6}$

Fasting causes changes in diet and physical activity, which is more clinically relevant for people with diabetes. ${ }^{7-10}$ In general, under controlled circumstances, intermittent fasting has shown to be beneficial to improve glucose homeostasis, insulin resistance, weight loss, and cardioprotection. ${ }^{11}$ However, it may throw off the delicate balance of food, water, and blood glucose levels in potentially harmful ways, increasing the risk of hypoglycemia and ketoacidosis, as well as thrombotic complications. ${ }^{6,8-13} \mathrm{~A}$ sudden change in dietary habits can cause harmful and unmanageable impacts on blood glucose levels, causing short- and long-term complications. ${ }^{13-7}$

The main objective of the study was to assess the dietary practices of people with T2DM during fasting, with a special focus on the common Hindu fasts: Navratri and Karvachauth. We also aimed to identify the eating patterns and nutritional assessment during fasting in subjects with T2DM among different religions in North India.

\section{Methods and participants}

This was a retrospective, cross-sectional, non-interventional, questionnaire-based study performed in the outpatient departments of three diabetes clinics in northern India (two from Delhi/National Capital Region and one from Bhopal). Patients who consented were subjected to a predesigned questionnaire. Exclusion criteria included people with diabetes other than T2DM, those suffering from any major disease, and those who were unwilling to participate.

Data were collected using a structured, multiple-choice, questionnaire that contained sections on socio-demographic profile (age, religion, monthly income, marital status, household type [nuclear/joint], and educational qualification), anthropometric assessments, medical therapy, and information on dietary and self-care practices during fasts. Among dietary practices, we specifically focused on collecting data related to food groups, with type of food items allowed, frequency of eating and general cooking methods used during the fasting period. The two most common Hindu fasts (Navratri and Karvachauth) were studied in detail. Both English- and Hindi-language questionnaires were used as per each participant's preference. Hindi translation was completed with the help of and validation by two language experts. The questionnaire was pilot tested on 30 subjects, who were not included in the study. Data were collected during the period of January-March, 2018.

\section{Statistical analysis}

Data were entered and consolidated in Microsoft Excel 2010 version. Categorical variables were presented in number and percentage, and continuous variables were presented as mean \pm standard deviation. The analysis was done using Statistical Package for Social Sciences (SPSS; Chicago, IL, USA) version 21.0 software.
Table 1: Demographic parameters of study subjects

\begin{tabular}{|l|l|}
\hline Parameters & Mean \pm SD \\
\hline Age, years & $54.23 \pm 11.86$ \\
\hline Males, $\mathrm{n}(\%)$ & $142(47.33)$ \\
\hline Females, $\mathrm{n}(\%)$ & $158(52.67)$ \\
\hline Height, $\mathrm{cm}$ & $160.29 \pm 9.57$ \\
\hline Weight, kg & $72.42 \pm 14.26$ \\
\hline Systolic blood pressure, $\mathrm{mmHg}$ & $125.03 \pm 4.49$ \\
\hline Diastolic blood pressure, $\mathrm{mmHg}$ & $75.88 \pm 8.56$ \\
\hline Fasting blood glucose, $\mathrm{mg} / \mathrm{dL}$ & $158.04 \pm 65.01$ \\
\hline Post-prandial blood glucose, $\mathrm{mg} / \mathrm{dL}$ & $222.63 \pm 98.66$ \\
\hline HbA1c, \% & $8.83 \pm 2.20$ \\
\hline
\end{tabular}

$N=300$.

HDA1C = glycated haemog/obin; SD = standard deviation

Table 2: Religion distribution of study subjects

\begin{tabular}{|l|l|l|}
\hline Religion & $\begin{array}{l}\text { Overall subjects } \\
(\mathrm{N}=300)\end{array}$ & $\begin{array}{l}\text { Subjects who fasted in the last year } \\
\text { among different religion }(\mathrm{n}=148)\end{array}$ \\
\hline Hindus & $229(76.33)$ & $115(77.70)$ \\
\hline Muslims & $33(11.00)$ & $22(14.86)$ \\
\hline Sikhs & $14(4.67)$ & $3(2.03)$ \\
\hline Jains & $7(2.33)$ & $1(0.68)$ \\
\hline Others & $17(5.67)$ & $7(4.73)$ \\
\hline
\end{tabular}

All values are presented as n (\%).

\section{Results}

A total of 300 subjects participated in the study (age $54.23 \pm 11.86$ years). The demographic and glycemic parameters of the study participants are shown in Table 1. The average time taken to complete the questionnaire was 15-20 minutes. Regarding pharmacotherapy, $93.33 \%$ of study subjects were taking metformin, $57.00 \%$ were on sulfonylureas, and $30.33 \%$ of subjects were on insulins, along with oral anti-diabetic medications. All subjects were receiving at least one drug for the management of hyperglycemia. Regarding complications, $19.66 \%$ of participants had peripheral neuropathy, 13.33\% had nephropathy, 5.00\% had retinopathy, while known coronary artery disease was present in $8.33 \%$ of subjects.

The distribution of study participants with respect to their religion and fasting practice are shown in Table 2 . The subjects were dominantly Hindus (76.33\%), followed by Muslims (11.00\%). The remaining $12.67 \%$ of participants were Sikh (4.67\%), Jain (2.33\%), and from other religions (5.67\%). Overall, 148 (49.33\%) participants observed at least one fast in the last year (2017-2018). Among the participants who observed fasts, $77.70 \%$ were Hindu, $14.86 \%$ were Muslim, $2.03 \%$ were Sikh, $0.68 \%$ were Jain, and $4.73 \%$ were from other religions (Christian and Buddhist).

Out of the subjects who observed fasts ( $n=148), 59$ (39.86\%) patients observed $1-5$ days of fasting, 28 (18.92\%) observed 6-10 days of fasting, and 14 (9.46\%) fasted for $>30$ days in past year (Table 3). Among Hindus, the most commonly 
Table 3: Frequency of fasts observed in the year 2017-2018 by study participants among different religions

\begin{tabular}{|l|l|l|l|}
\hline $\begin{array}{l}\text { Number of days } \\
\text { fast observed }\end{array}$ & $\begin{array}{l}\text { Overall subjects who } \\
\text { fasted }(n=148)\end{array}$ & $\begin{array}{l}\text { Males } \\
(n=45)\end{array}$ & $\begin{array}{l}\text { Females } \\
(n=103)\end{array}$ \\
\hline $1-5$ & $59(39.86)$ & $13(28.89)$ & $46(44.66)$ \\
\hline $6-10$ & $28(18.92)$ & $7(15.56)$ & $21(20.39)$ \\
\hline $11-15$ & $11(7.43)$ & $6(13.33)$ & $5(4.85)$ \\
\hline $16-20$ & $15(10.14)$ & $4(8.89)$ & $11(10.68)$ \\
\hline $21-25$ & $15(10.14)$ & $9(20.00)$ & $6(5.83)$ \\
\hline $26-30$ & $6(4.05)$ & $2(4.44)$ & $4(3.88)$ \\
\hline$>30$ & $14(9.46)$ & $4(8.89)$ & $10(9.71)$ \\
\hline
\end{tabular}

All values are presented as $n(\%)$.

Table 4: Type of fasts observed in last year by study participants among different religions

\begin{tabular}{|l|l|l|l|}
\hline Fast & Overall subjects & Male & Female \\
\hline Hindu & $n=229$ & $n=113$ & $n=116$ \\
\hline Navratris & $79(34.50)$ & $22(19.47)$ & $57(49.14)$ \\
\hline Karvachauth & $71(31.00)$ & $1(0.88)$ & $70(60.34)$ \\
\hline Mahashivratri & $60(26.20)$ & $19(16.81)$ & $41(35.34)$ \\
\hline Janamashtmi & $44(19.21)$ & $15(13.27)$ & $29(25.00)$ \\
\hline Ahoi Ashtami & $41(17.90)$ & $3(2.65)$ & $38(32.76)$ \\
\hline Ekadashi & $14(6.11)$ & $4(3.54)$ & $10(8.62)$ \\
\hline Monday fast & $14(6.11)$ & $3(2.65)$ & $11(9.48)$ \\
\hline Muslim & $n=33$ & $n=15$ & $n=18$ \\
\hline Ramadan & $22(66.67)$ & $14(93.33)$ & $8(44.44)$ \\
\hline Jain & $n=7$ & $n=3$ & $n=4$ \\
\hline Digambarupvas & $1(14.29)$ & 0 & $1(25.00)$ \\
\hline Ekasana & $1(14.29)$ & 0 & $1(25.00)$ \\
\hline
\end{tabular}

All values are presented as $n(\%)$.

observed fasts were Navratri (by 19.47\% of males, $49.14 \%$ of females) and Karvachauth ( $0.88 \%$ of males, $60.34 \%$ of females). Among Muslims, Ramadan was the most common fast (66.67\%), and among Jains, Digambarupvas and Ekasana (14.29\% each) were common fasts (Table 4).

The common dietary and self-care practices followed during fasting are shown in Table 5. Out of all the participants, $40.54 \%$ had the perception that their calorie consumption decreased, and $33.11 \%$ thought their calorie consumption increased during the period of fasting. Only $1.35 \%$ of participants consulted their dietician for pre-assessment and dietary modifications. The majority of the patients (85.81\%) believed that their weight remained neutral $(72.42 \pm 14.26 \mathrm{~kg}$ [this is an estimation of weight; as this was a retrospective study, exact weight was not measured at baseline]) during fasting. Despite the fact that the majority of patients (57.00\%) monitored blood glucose, only $4.05 \%$ actually checked their glucose levels during their last fast. The majority of the patients (66.22\%) continued their exercise routine during periods of fast.

The detailed dietary practices followed during the most common Hindu fasts (Navratri and Karvachauth) were explored further. As summarized in Table 6, 65.82\% of participants reported that they ate three times
Table 5: Dietary and self-care practices and beliefs of participants who fasted in the year 2017-2018

\begin{tabular}{|l|l|}
\hline Dietary and self-care practices and beliefs & $n(\%)$ \\
\hline Believed that consumption of food decreased & $60(40.54)$ \\
\hline Believed that consumption of food increased & $49(33.11)$ \\
\hline Consulted dietician pre-fast for dietary modifications & $2(1.35)$ \\
\hline Perception of consistency in body weight & $127(85.81)$ \\
\hline Continued routine exercise during fast & $98(66.22)$ \\
\hline Missed diabetes medications or insulins during fasting & $90(60.81)$ \\
\hline Performed home glucose monitoring during fast & $6(4.05)$ \\
\hline
\end{tabular}
$n=148$

Table 6: Dietary patterns followed among the subjects who observed fasts during Navratri and Karvachauth

\begin{tabular}{|c|c|c|}
\hline Dietary patterns & $\begin{array}{l}\text { Navratri } \\
\mathrm{n}=79\end{array}$ & $\begin{array}{l}\text { Karvachauth } \\
n=71\end{array}$ \\
\hline \multicolumn{3}{|l|}{ Frequency of eating in common Hindu fasts } \\
\hline Once a day (one meal with no snack) & $12(15.19)$ & $35(49.30)$ \\
\hline Twice a day (one meal with one snack) & $13(16.45)$ & $25(35.21)$ \\
\hline Thrice a day (one meal with two small snacks) & $52(65.82)$ & $11(15.49)$ \\
\hline Anytime (multiple time meals/snacks as desired) & $2(2.53)$ & 0 \\
\hline \multicolumn{3}{|l|}{ Types of food consumed by items consumed } \\
\hline Ready-made items & $3(3.80)$ & $1(1.41)$ \\
\hline Packet items & $6(7.59)$ & $3(4.23)$ \\
\hline Home-made items & 78 (98.73) & $68(95.77)$ \\
\hline \multicolumn{3}{|l|}{ Food groups consumed more than once } \\
\hline Cereals & $8(10.13)$ & $6(8.45)$ \\
\hline Pulses & $1(1.27)$ & 0 \\
\hline Milk and milk products & $73(92.41)$ & $40(56.34)$ \\
\hline Vegetables & $6(7.59)$ & $1(1.41)$ \\
\hline Fruits & $39(49.37)$ & $12(16.90)$ \\
\hline Oil & $22(27.85)$ & $18(25.35)$ \\
\hline Sugar & $31(39.24)$ & $20(28.17)$ \\
\hline \multicolumn{3}{|l|}{ Non-homemade foods } \\
\hline Sweets & $49(62.03)$ & $50(70.42)$ \\
\hline Special thalis & $5(6.33)$ & $1(1.41)$ \\
\hline \multicolumn{3}{|l|}{ Beverages } \\
\hline Soft drinks & $22(27.85)$ & $15(21.13)$ \\
\hline Drinks with added sugar & $33(41.77)$ & $35(49.30)$ \\
\hline Non-sweetened home-made beverages & $44(55.70)$ & $29(40.85)$ \\
\hline
\end{tabular}

All values are presented as $n(\%)$.

a day (one meal with two small snacks, such as fruits or tea) during Navratri. During Navratri and Karvachauth fasts, $15.19 \%$ and $49.30 \%$ of participants, respectively, ate only once a day (one meal with no snack), while $16.45 \%$ and $35.21 \%$ ate twice a day (one meal with one snack). Most of the participants reported that they ate home-made items instead of ready-made outside food and packet items during Navratri and Karvachauth $(98.73 \%$ and $95.77 \%$ of participants, respectively). Milk and milk products, and fruit were the most commonly reported food groups consumed. The preferred cereals during Navratri were 
buckwheat flour (38.27\%), amaranth flour (9.34\%), water chestnut flour (26.12\%) and barnyard millet (20.13\%); while during Karvachauth, wheat flour was consumed by $45.60 \%$. Only $2.62 \%$ consumed other cereals in Karvachauth. Direct intake of sugar in the form of sweets/desserts, as well as beverages containing sugar, juices, and soft drinks, was also very common, while pulses were the food group that was least eaten.

Among participants who observed Navratri, $47.64 \%$ consumed food prepared by frying (shallow or deep frying); 62.03\% consumed sweets, Indian desserts (rasmallai, kheer, sweet rice, rasgulla, barfi, kalakand), and jaggery; $41.77 \%$ consumed sugar-added beverages (tea, lime soda, milk, buttermilk, shakes); and $27.85 \%$ consumed soft drinks. Among participants who observed Karvachauth, 38.90\% consumed food prepared by frying (shallow or deep frying); $70.42 \%$ consumed sweets, Indian desserts (like barfi, rasmallai, kheer, rasgulla), and jaggery; $49.30 \%$ consumed sugar-added beverages; and $21.13 \%$ consumed soft drinks.

\section{Discussion}

This cross-sectional study was conducted to assess the dietary and self-care practices during religious fasts in people with T2DM from northern India, with more focus on the common Hindu fasts. Our study found that fasting practices are common in subjects with T2DM from all religions. The most common Hindu fasts were Navratri and Karvachauth. Navratri was observed commonly among both genders, while Karvachauth was found to be predominantly observed among women. This showed that Hindu females, overall, tend to observe more fasts, compared to Hindu males. The study also showed significant erratic dietary practices during days of fasts. This signifies the need to educate people with T2DM, and improve self-care practices among them and their families.

Exploring dietary practices during fasts, it was seen that the frequency of eating during fasts varied among different religions, as well as the type of fast. Most of the participants reported eating three times a day (one meal with two small snacks) during fasts. The composition of that meal is reflected to be high in glycemic load, which may elevate post-prandial blood glucose levels. The recommended pattern of 5-6 meals $(3+3$ meal pattern, recommended with respect to the achievement of optimum glycemic control) was not followed by any patient during fasting. In our study, only two (1.35\%) participants consulted their doctor/dietician for pre-assessment and dietary modifications. The literature on Ramadan fasting has also similarly reported erratic meal patterns, medical ignorance, and deteriorating glycemic control among people with diabetes. ${ }^{14-20} \mathrm{~A}$ study conducted by Al-Arouj et al. in 2010 highlighted general considerations on individualization, frequent monitoring of glycemia, nutrition, and exercise, for the management of diabetes during Ramadan. ${ }^{21}$

The food groups most consumed during Navratri and Karvachauth fasts were milk and milk products, fruits and cereals. Fats and sugars were also reported to be significantly consumed. As a part of medical nutrition therapy for optimal glycemic control and prevention of complications, it is advised to include an adequate proportion of food groups to meet the dietary recommendations of nutrients. Dietary recommendations for food groups and macronutrients for people with diabetes have previously been defined. ${ }^{21}$ Regarding food groups, half the food plate should consist of fruits and vegetables, while the other half is divided between whole grains or flour of low glycemic index, and lean sources of protein with carbohydrate distribution and adequate intake of non-fat or low-fat dairy source throughout the day. These principles remain similar even during the fasting period. However, the participants in the present study displayed erratic food-group consumption, carbohydrate distribution, and glycemic load of meals during fasts. The intake of certain food groups, i.e., cereals, pulses and vegetables, was inadequate, while the intake of fats and sugars was much higher than recommended. In our study, we specifically studied the flours used during the fasting period, as this is the most important source of carbohydrate for most Indians. Wheat flour is the most commonly consumed flour in non-fasting days among Indians. The flours consumed during fasting days had a similar glycemic index to that of wheat flour.

In our study, this change in food groups is likely to cause significant changes in blood-glucose levels, which is likely to be compounded by inconsistencies in the amount eaten and the timing of meals. Additionally, this pattern is unlikely to meet the nutritional needs of these individuals. ${ }^{4}$ A study published by Zainudin et al. in 2017 on Ramadan fasting in people with diabetes also showed that patients had misconceptions about food groups and the impact of different food groups on blood glucose levels.22

The most common cooking method was frying (shallow and deep frying) with significant usage of direct sugar sources, which is likely to result in making the meal more calorie-dense, disturbing the post-prandial blood glucose levels. In contrast to the findings of Yaacob et al., direct intake of sugar in the form of sweets/desserts, as well as sugar-containing beverages, juices and soft drinks, was very common in our study. ${ }^{19}$ Hence, the dietary pattern showed imbalance in nutritional compositions and erratic meal patterns followed during fasts. The judicious practice of basic dietary recommendations can be easily followed during fasting and feasting, given fast-specific counselling. 4,6,23-5

To the best of our knowledge, this is the first study to focus on the fasting practices of people with T2DM among Hindus in northern India. There were several limitations of this study which should be noted. This was a cross-sectional study based on retrospective questionnaire-based information. The study involved a volunteer group, which limits generalizability. Religion-based, as well as gender-based, sub-group analysis was limited by the small number of patients. Also, data on calorie consumption using detailed methodology could not be collected.

\section{Conclusion}

Erratic dietary practices are common during fasting among subjects with T2DM among Hindu religion in northern India. The majority of participants in this study did not discuss their fasting habits with their diabetes care team. Diabetes care teams should discuss fasts with their patients with T2DM. They should tailor this information based on the patient's religion and provide them with information regarding diet during days of fast. $\square$ 
1. Akbani MF, Saleem M, Gadit WU, et al. Fasting and feasting safely during Ramadan in the patient with diabetes. Pract Diabetes Int 2005;22:100-4.

2. Kalra S, Bajaj S, Gupta Y, et al. Fasts, feasts and festivals in diabetes-1: glycemic management during Hindu fasts. Indian J Endocrinol Metab. 2015;19:198-203.

3. Census 2011. Religion Census 2011. Available at: www.census2011.co.in/religion.php (accessed October 31, 2019).

4. Gupta L, Khandelwal D, Singla R, et al. Pragmatic dietary advice for diabetes during Navratris. Indian J Endocr Metab. 2017;21:231-7.

5. Birdie AK. Impact of Navratras festival on the subjective wellbeing of vegetarian customers in hospitality sector. Int I SOC SC Manage. 2015;2:333-8.

6. Dutta D, Biswas K, Sharma M, et al. Managing diabetes during Navratris with special focus on Durga pujas. JOSH Diabetes. 2015;3:84.

7. Sircar AR, Sircar S, Sircar J, Misra S. Patients' concepts and attitudes about diabetes. I Diabetes Complications. 2010;24:398-403.

8. Almalki MH, Alshahrani F. Options for controlling type 2 diabetes during Ramadan. Front Endocrinol (Lausanne). 2016;7:32.

9. Amin S, Saadi HR. Practical management of diabetic patient during Ramadan. MJN. 2017;8:42-4.

10. Elhadd TA, AlAmoudi AA. Recommendations for management of diabetes during Ramadan. Diabetes Care. 2006;29:744-5.

11. Kannan $\mathrm{S}$, Mahadevan $\mathrm{S}$, Seshadri $\mathrm{K}$, et al. Fasting practices in Tamil Nadu and their importance for patients with diabetes. Indian J Endocrinol Metab. 2016;20:858-62.

12. Kelley DE. Sugars and starch in the nutritional management of diabetes mellitus. Am I Clin Nutr. 2003;78:858S-64S.

13. Jaleel MA, Raza SA, Fathima FN, Jaleel BN. Ramadan and diabetes: As-Saum (The fasting). Indian J Endocrinol Metab. 2011;15:268-73.

14. Trepanowski JF, Bloomer RJ. The impact of religious fasting on human health. Nutr J. 2010:9:57.

15. American Diabetes Association. Standards of medical care in diabetes-2016 abridged for primary care providers. Clin Diabetes. 2016;34:3-21

16. Bravis V, Hui E, Salih S, et al. Ramadan Education and Awareness in Diabetes (READ) programme for Muslims with type 2 diabetes who fast during Ramadan. Diabet Med. 2010;27:327-31.

17. Azizi F. Islamic fasting and health. Ann Nutr Metab. 2010;56:273-82.

18. Gupta L, Khandelwal D, Kalra S. Increasing fibre in South Asian Diets. J Pak Med Assoc. 2018;68:1135-6.
19. Yaacob N, Ismail AA, Bebaker WM. Knowledge, attitude, and practice of type 2 diabetes mellitus patients on Ramadan fastin at Hospital Universiti Sains Malaysia. J ISlam Med Assoc N Am. 2007;39.

20. Vasan SK, Karol R, Mahendri NV, et al. A prospective assessment of dietary patterns in Muslim subjects with type 2 diabetes who undertake fasting during Ramadan. Indian I Endocrinol Metab. 2012;16:552-7.

21. Al-Arouj M, Assaad-Khalil S, Buse J, et al. Recommendations for management of diabetes during Ramadan: update 2010. Diabetes Care. 2010;33:1895-902.

22. Zainudin SB, Ang DY, Soh AW. Knowledge of diabetes mellitus and safe practices during Ramadan fasting among Muslim patients with diabetes mellitus in Singapore. Singapore Med J. 2017;58:246-52

23. Siddiqui NI, Kamrul-Hasan M, Hossain MA, et al. Ramadan Perspective Epidemiology and Education in Diabetes (RAPEED) Study. Mymensingh Med J. 2017;26:256-65.

24. Gupta L, Khandelwal D. Pragmatic selection of cooking oils. J Pak Med Assoc. 2017;67:957-8.

25. Gupta L Khandelwal D, Kalra S. Carbohydrate counting-1: South Asian framework. J Pak Med Assoc. 2017;67:1296-8. 